\title{
A novel approach for the adsorption of cadmium ions in aqueous solution by dead calcareous skeletons
}

\begin{abstract}
Heavy metal contamination in water causes problems to the environment and the deterioration of human health. Various types of water remediation methods have been conducted to counter this problem and to reduce the toxicity risk in water. As the conventional treatment process does not completely remove pollutants in the water, alternative purification methods have been studied to improve the treatment process. In this present study, batch experiments were conducted to evaluate the ability of dead calcareous skeleton in removing cadmium ions $(\mathrm{Cd}(\mathrm{II}))$ from aqueous solution. The factors affecting adsorption were evaluated in respect of adsorbent size, contact time, adsorbent dosage, $\mathrm{pH}$, and initial concentration to determine the optimum conditions for $\mathrm{Cd}(\mathrm{II})$ removal. The optimum size of CS was $710 \mu \mathrm{m}$ and the equilibrium was achieved at $600 \mathrm{~min}$. The most favorable dosage concentration was $20 \mathrm{~g} / \mathrm{L}$. The optimum $\mathrm{pH}$ for the $\mathrm{Cd}(\mathrm{II})$ adsorption was 6.42, which is the initial $\mathrm{pH}$ of $\mathrm{Cd}$ (II) solution. The adsorption capacity of CS appeared to be higher when the initial concentration Cd(II) increased above $1 \mathrm{mg} / \mathrm{L}$. The experimental data fitted better in the Freundlich isotherm than in the Langmuir isotherm but the bonding was rather weak. The results from this study demonstrate that dead calcareous skeletons have considerable potential in water treatment applications for the metal removal process. In addition, the cost of chemical usage can be reduced due to the natural characteristics of adsorbents, which are able to alter the $\mathrm{pH}$ of the solution so that it is favorable for optimum adsorption capacity.
\end{abstract}

Keyword: Cadmium; Dead calcareous skeletons; Adsorption capacity; Removal efficiency; Batch experiment 